\title{
Optimum Design of TMD System for Tall Buildings
}

\author{
Ahmed Abdelraheem Farghaly and Mahmoud Salem Ahmed \\ Faculty of Industrial Education, Sohag University, Egypt \\ Correspondence should be addressed to Ahmed Abdelraheem Farghaly, khodary20002000@yahoo.com
}

Received 26 February 2012; Accepted 23 April 2012

Academic Editors: F. A. Branco and J. Mohammadi

Copyright ( 2012 A. A. Farghaly and M. Salem Ahmed. This is an open access article distributed under the Creative Commons Attribution License, which permits unrestricted use, distribution, and reproduction in any medium, provided the original work is properly cited.

\begin{abstract}
As tall buildings keep becoming taller, they become more susceptible to dynamic excitations such as wind and seismic excitations. In this paper, design procedure and some current applications of tuned mass damper (TMD) are discussed. A symmetrical moment resistance frame (MRF) twenty storey three-dimensional model were modeled in SAP2000 and a TMD was placed on its top and through it to study its effects on the structural response due to seismic excitations and using time history analysis with and without the TMD. The study indicates that the response of structure such as storey displacements and shear force of columns can be dramatically reduced by using TMD (groups of TMDs) devices especially with a specific arrangement in the model. The study illustrates the group of four TMDs distributed on the plan (interior) which can be effective as R.C. core shear wall.
\end{abstract}

\section{Introduction}

The application of passive Tuned Mass Damper (TMD) is an attractive option in reducing excessive floor vibrations. A TMD consists of a mass, spring, and dashpot, as shown in Figure 1, and is typically tuned to the natural frequency of the primary system [1]. When large levels of motion occur, the TMD counteracts the movements of the structural system. The terms $m_{1}, k_{1}, c_{1}$, and $X_{1}$ represent the mass, stiffness, damping, and displacement of the floor, while $m_{2}, k_{2}, c_{2}$, and $X_{2}$ represent the mass, stiffness, damping, and displacement of the TMD and $F(t)$ represents the excitation force.

As the two masses move relative to each other, the passive damper is stretched and compressed, reducing the vibrations of the structure by increasing its effective damping.

TMD systems are typically effective over a narrow frequency band and must be tuned to a particular natural frequency.

They are not effective if the structure has several closely spaced natural frequencies and may increase the vibration if they are off-tuned [2].

The natural frequency of the primary system can be divided to a lower $\left(f_{1}\right)$ and higher $\left(f_{2}\right)$ frequency by attaching a spring mass tuned to the same fundamental natural frequency $\left(f_{n}\right)$ of the primary system as shown in Figure 2.
The most significant design variable of the damper is the mass ratio $(\mu)$ as defined in (1). When the mass ratio increases, the TMD becomes more effective and robust [3]. In most applications the mass ratio is designed to be in the range of $1-10 \%$.

$$
\mu=\frac{m_{2}}{m_{1}}
$$

In the design of a TMD, the optimum natural frequency of the damper $\left(f_{d}\right)$ is defined by:

$$
f_{d}=\frac{f_{n}}{1+\mu},
$$

and the optimum damping ratio of damper $\left(\zeta_{\text {opt }}\right)$ can be found as follows:

$$
\zeta_{\mathrm{opt}}=\sqrt{\frac{3 \mu}{8(1+\mu)^{3}}}
$$

If there is zero damping then resonance occurs at the two undamped resonant frequencies of the combined system $\left(f_{1}\right.$ and $f_{2}$ ). The other extreme case occurs when there is infinite 


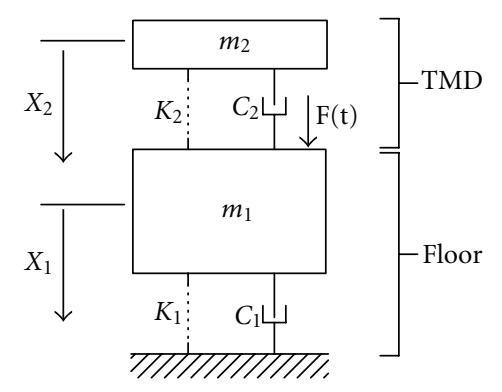

FIgURE 1: Schematic representation of a two-DOF system.

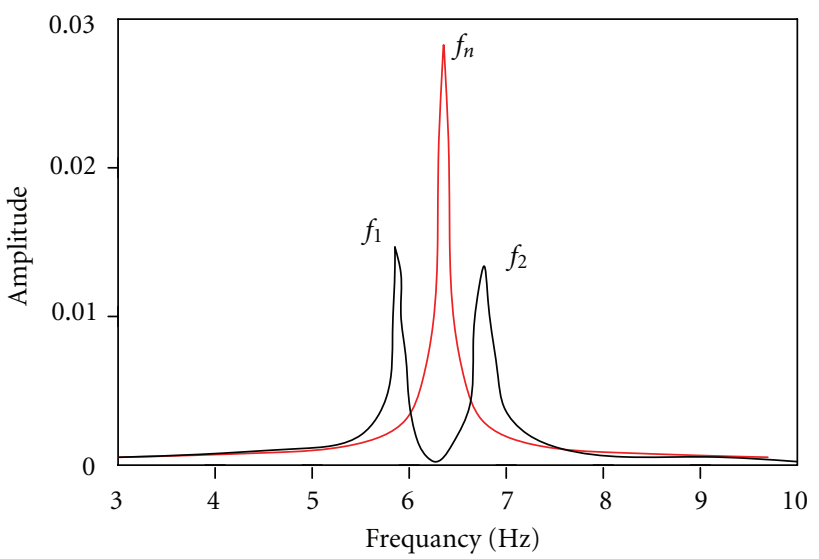

Figure 2: Example demonstrating the effectiveness of a TMD.

damping, which has the effect of locking the spring $\left(k_{2}\right)$; in this case the system has one degree of freedom with stiffness of $\left(k_{1}\right)$ and a mass of $\left(m_{1}+m_{2}\right)$. Using an intermediate value of damping such as $\zeta_{\text {opt }}$, somewhere between these extremes, it is possible to control the vibration of the primary system over a wider frequency range [4].

In the study of Wang and Lin [5], they have concluded that TMD system is effective in reducing the responses of displacement and velocity of the building structure.

Tezcan and Uluca [6] examined the application of viscoelastic dampers for three kinds of buildings to reduce earthquake response of them: (a) a 7-storey steel frame, (b) a 10-storey reinforced concrete frame, and (c) a 20-storey reinforced concrete frame. They have concluded that the numerical results on three example frames clearly indicate that the viscoelastic dampers reduce the seismic response of structures in an extremely efficient way. In addition, it has been seen that the viscoelastic dampers in tall buildings are most effective for high-frequency earthquakes like El Centro, but for low-frequency earthquakes loads, the viscoelastic devices are less effective.

The effectiveness of a single TMD is decreased significantly by the off-tuning or the off-optimum damping in the TMD. That is, a single TMD is not robust at all. Furthermore, the dynamic characteristics of structures will change under strong earthquakes due to a degradation of the structure stiffness. This change will degrade the performance of a single TMD considerably owing to the offset in the tuning of the frequency and/or in the damping ratio. As a result, the utilization of more than one tuned mass damper with different dynamic characteristics has been proposed in order to improve the effectiveness and robustness of a single TMD. Iwanami and Seto [7] proposed dual tuned mass dampers (2TMDs) and conducted a research on the optimum design of 2 TMDs for harmonically forced vibration of the structure. It was shown that $2 \mathrm{TMD}$ are more effective than a single TMD. However, the effectiveness was not significantly improved. Recently, multiple tuned mass dampers (MTMDs) with distributed natural frequencies were proposed by Igusa and $\mathrm{Xu}[8]$. They derived a simple formula of equivalent additional damping and an integral form for the impedance based on an asymptotic analysis technique. Based on the various combinations of the stiffness, mass, damping coefficient, and damping ratio in the MTMD, five MTMD models have been presented by Li [9]. Through implementing the minimization of the minimum values of the maximum displacement dynamic magnification factors and the minimization of the minimum values of the maximum acceleration dynamic magnification factors, it has been shown that the MTMD with the identical stiffness and damping coefficient but unequal mass and damping ratio can provide better effectiveness and wider optimum frequency spacing (i.e., higher robustness against the change or the estimation error in the structural natural frequency) with respect to the rest of the MTMD models [10].

Likewise, the studies by $\mathrm{Li}$ and Liu [10] have disclosed further trends of both the optimum parameters and effectiveness and further provided suggestion on selecting the total mass ratio and total number of the MTMD with the identical stiffness and damping coefficient but unequal mass and damping ratio. More recently, in terms of the uniform distribution of system parameters, instead of the uniform distribution of natural frequencies, eight new MTMD models have been proposed to seek for the MTMD models without the near-zero optimum average damping ratio. Six MTMD models without the near-zero optimum average damping ratio have been found. The optimum MTMD with the identical damping coefficient and damping ratio but unequal stiffness and with the uniform distribution of masses has been found able to render better effectiveness and wider optimum frequency spacing with respect to the rest of the MTMD models. Likewise it is interesting to 
TABLE 1: Optimum TMD parameters for the three MDOF structures [12].

\begin{tabular}{lcccccccc}
\hline No. of storey & $\mu$ & $\beta$ & $f$ & $\zeta$ & $\zeta_{1}$ & $\zeta_{2}$ & $\left(\zeta_{1}+\zeta_{2}\right) / 2$ & $\Phi$ \\
\hline 10 & 0.05 & 0.02 & 0.93 & 0.33 & 0.18 & 0.18 & 0.17 & 1.36 \\
6 & 0.08 & 0.05 & 0.91 & 0.41 & 0.24 & 0.24 & 0.22 & 1.33 \\
3 & 0.10 & 0.00 & 0.87 & 0.37 & 0.20 & 0.20 & 0.18 & 1.23 \\
\hline
\end{tabular}

know that the two previous mentioned MTMD models can approximately reach the same effectiveness and robustness [11].

Mathematical modeling of the tested model, with and without TMDs, has been done using CSI SAP2000 computer program. The tested model is modeled as 3D frame structure, while the TMDs, which were installed at the top and through of the tested model on a steel base plate, are modeled using link elements for springs and dampers.

Sadek et al. [12] found that the tuning ratio $f$ for a MDOF system is nearly equal to the tuning ratio for an SDOF system for a mass ratio of $\mu \Phi$, where $\Phi$ is the amplitude of the first mode of vibration for a unit model participation factor computed at the location of the TMD, that is, $f_{\mathrm{MDOF}}(\mu)=$ $f_{\mathrm{SDOF}}(\mu \Phi)$. Equation (4) for the tuning ratio is as follows:

$$
f=\frac{1}{1+\mu \Phi}\left[1-\beta \sqrt{\frac{\mu \Phi}{1+\mu \Phi}}\right] .
$$

The TMD damping ratio is also found to correspond approximately to the damping ratio computed for a SDOF system multiplied by $\Phi$, that is, $\zeta_{\mathrm{MDOF}}(\mu)=\Phi \zeta_{\mathrm{SDOF}}(\mu)$. Equation (5) is as follows:

$$
\zeta=\Phi\left[\frac{\beta}{1+\mu}+\sqrt{\frac{\mu}{1+\mu}}\right] .
$$

The above equation indicates that the best location for a TMD is where it results in the largest $\zeta$, that is, at the level where $\Phi$ and consequently the damping in the TMD and in the first two modes are maximums. Since, in most cases, the first mode dominates the response, it is the largest. Similar observations have also been reported by Villaverde [13]

Table 1 shows the application of the above equations on 3-, 6-, and 10-storey building. The optimum values of $f$ and $\zeta$ for the three structures are given in Table 1 along with the resulting damping ratios in the first two modes of vibration. As shown in Table 1, the damping ratios are extremely close to each other and are greater than $(\zeta+\beta) / 2$. It should be mentioned that the TMDs attached to the structures affected only the damping in the first two modes and had no effect on the other modes which were assumed to have a zero damping [12].

The good design of any structure is safety, serviceability, and economy. Achieving better design of structures in seismic regions is very important and difficult. Uncertainty and unpredictability of when, where, and how an earthquake will be happen will increase the overall difficulties. The goal of this research is studying the seismic behavior of tall building structures by TMDs.
The optimum parameters used in this paper for TMDs of The optimum frequency ratio $\alpha_{\mathrm{opt}}$, damping ratio $\zeta$, spring stiffness $k_{d}$, and damping $c_{d}$ as Zahrai and Ghannadi-Asl [14] are in the following:

$$
\begin{gathered}
\alpha_{\mathrm{opt}}=\frac{1}{1+\mu} \sqrt{\frac{2-\mu}{2}}, \\
\zeta_{\mathrm{opt}}=\sqrt{\frac{3 \mu}{8(1+\mu)} \sqrt{\frac{2}{2-\mu}},} \\
k_{d}=4 \pi^{2} \mu \alpha^{2} \frac{m_{d}}{T_{d}^{2}}, \\
c_{d}=4 \pi \mu \alpha \zeta_{\mathrm{opt}} \frac{m_{d}}{T_{d}} .
\end{gathered}
$$

In Den Hartog's derivation of optimal damper parameters, it is assumed that the main mass is undamped. In the presence of damping for the main mass, no closedform expressions can be derived for the optimum damper parameters. However, they may be obtained by numerical trials with the aim of achieving a system with the smallest possible value of its higher response peak [14].

\section{Objectives}

The objectives of this study can be listed as follows:

(a) remodeling of a tall building structure (MRF building) by TMD system,

(b) determining the effects earthquake generated from El Centro on seismic behavior of tall buildings,

(c) study the effect of distributing the TMD on the plan and through the model to give the best distribution in the model,

(d) using a TMD system as alternative system to resist the lateral force represented by earthquake.

A lateral load resistance system is tube-in-tube or hullcore structure. This is different type of the frame tube structure. It consists of an outer framed tube, the hull together with an internal elevator and service core. In addition, there are some basic assumptions that are made during the modeling and studying, which are listed as follows:

(i) column sizes from the first floor to the top are of the variable (get smaller) size (see Table 2), 


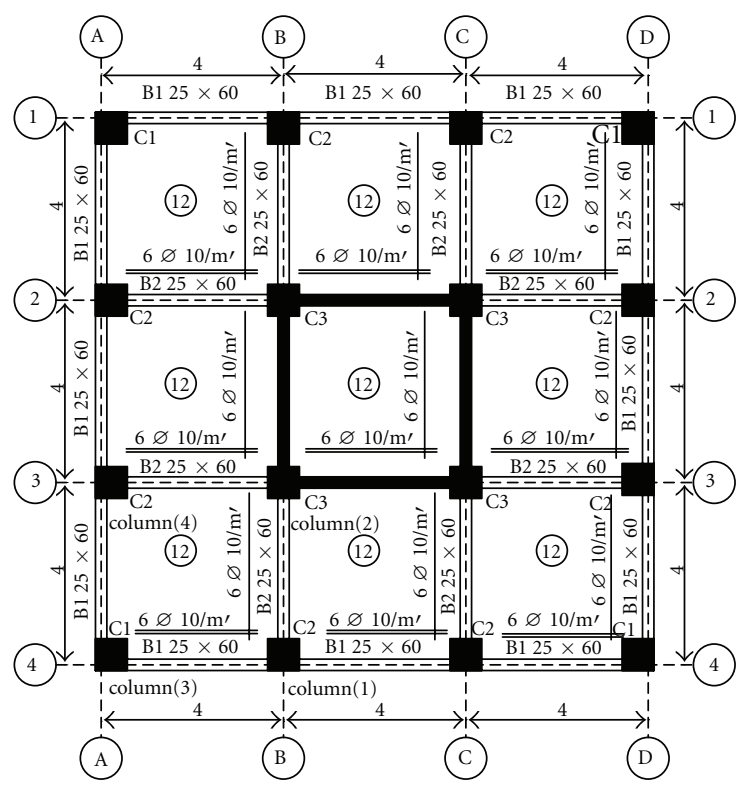

(i) Shear wall model (SW)

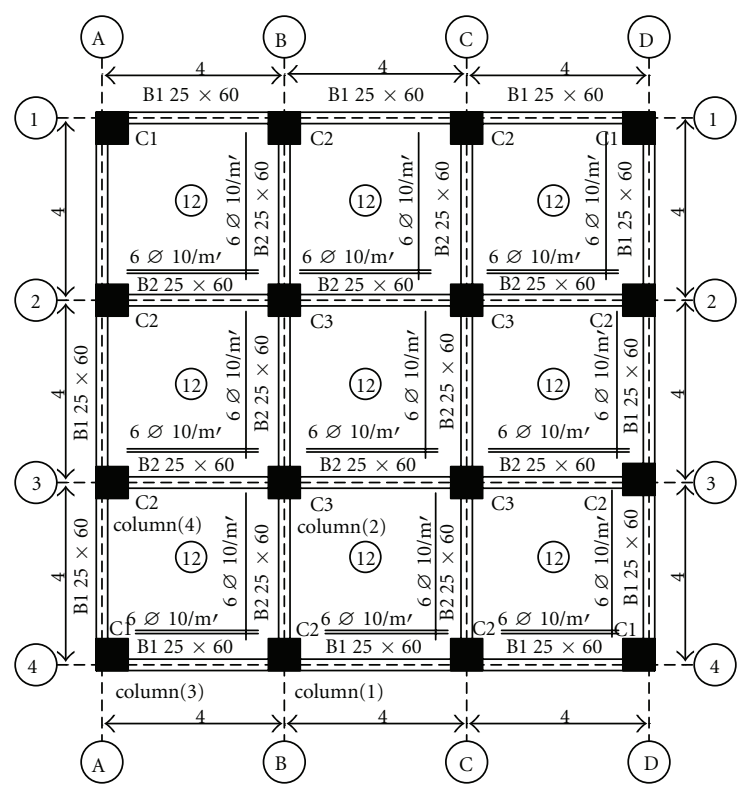

(ii) Bar MRF

FIGURE 3: Typical structural plain of each floor of the 20-storey building model.

TABLE 2: Dimension of reinforced concrete elements of the MRF building (dimension in $\mathrm{cm}$ ).

\begin{tabular}{lccccc}
\hline \multirow{2}{*}{ Floor } & \multicolumn{3}{c}{ Dimension } \\
& C1 & C2 & C3 & B1 & B2 \\
\hline $1,2,3$ & $70 \times 70$ & $70 \times 70$ & $70 \times 70$ & $25 \times 60$ & $25 \times 60$ \\
$4,5,6$ & $65 \times 65$ & $65 \times 65$ & $65 \times 65$ & $25 \times 60$ & $25 \times 60$ \\
$7,8,9$ & $60 \times 60$ & $60 \times 60$ & $60 \times 60$ & $25 \times 60$ & $25 \times 60$ \\
$10,11,12$ & $55 \times 55$ & $55 \times 55$ & $55 \times 55$ & $25 \times 60$ & $25 \times 60$ \\
$13,14,15$ & $50 \times 50$ & $50 \times 50$ & $50 \times 50$ & $25 \times 60$ & $25 \times 60$ \\
$16,17,18$ & $45 \times 45$ & $45 \times 45$ & $45 \times 45$ & $25 \times 60$ & $25 \times 60$ \\
19,20 & $40 \times 40$ & $40 \times 40$ & $40 \times 40$ & $25 \times 60$ & $25 \times 60$ \\
\hline
\end{tabular}

(ii) stiffness of floor slabs, beams, and columns of the frame make rigid diaphragm in horizontal plan,

(iii) the frames have been modeled as rigid frames (the connection between radial beams to core are pinned),

(iv) all restrains that have been modeled are assumed to be fixed,

(v) only ground acceleration of $X$ and $Y$ directions is taken into account.

\section{Model Definition}

A twenty-storey concrete MRF building $\left(f_{s}=2000 \mathrm{~kg} / \mathrm{cm}^{2}\right.$, $f_{c}=100 \mathrm{~kg} / \mathrm{cm}^{2}$ ) with specific dimensions as shown in Table 2 was tested.

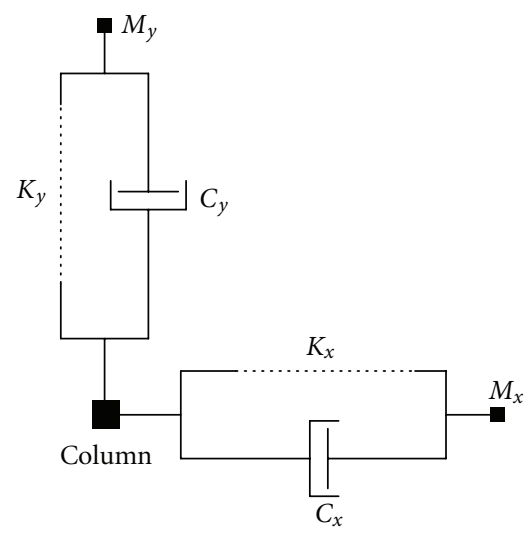

Figure 4: Plan of TMD components in $X$ and $Y$ directions.

Figure 3 shows the typical structural plan of the repeated floors for the total 20-storeys.

Evidently, much progress has been extended in recent years in terms of the studies on the MTMD for mitigating oscillations of structures. However, in most studies on both the TMD and MTMD, it is assumed that a structure vibrates in only one direction or in multiple directions independently with its fundamental modal properties to design the TMD or the MTMD. This assumption simplifies the analysis of a system and the synthesis of a controller. The TMD attached to columns so it will affect the values of the displacements and base shear in each floor level in both directions $X$ and $Y$ (in plan) because the building will vibrate in both direction $X$ and $Y$ (direction of earthquake EW and SN) (see Figure 4).

The MTMD is shown to be more effective in mitigating the oscillations of structures with respect to a single TMD 
TABLE 3: Properties of TMDs used in testing models in both $X, Y$ directions as Zahrai and Ghannadi-Asl [14].

\begin{tabular}{lcccccc}
\hline No. TMDs & $m_{\text {TMD }}($ ton $)$ & $\mu \%$ & $\alpha_{\text {opt }}$ & $\zeta_{\text {opt }}$ & $k_{d}$ & $c_{d}$ \\
\hline 1 & 216 & 0.050 & 0.940 & 0.051 & 152.789 & 83.029 \\
2 & 108 & 0.025 & 0.970 & 0.026 & 40.597 & 21.797 \\
4 & 54 & 0.013 & 0.985 & 0.013 & 10.467 & 5.586 \\
5 & 43.2 & 0.010 & 0.988 & 0.011 & 6.744 & 3.594 \\
8 & 27 & 0.006 & 0.992 & 0.007 & 2.658 & 1.414 \\
10 & 21.6 & 0.005 & 0.994 & 0.005 & 1.706 & 0.907 \\
16 & 13.5 & 0.003 & 0.996 & 0.003 & 0.670 & 0.356 \\
20 & 10.8 & 0.002 & 0.997 & 0.003 & 0.429 & 0.228 \\
32 & 6.75 & 0.002 & 0.998 & 0.002 & 0.168 & 0.089 \\
40 & 5.4 & 0.001 & 0.998 & 0.001 & 0.108 & 0.057 \\
80 & 2.7 & 0.001 & 0.999 & 0.001 & 0.027 & 0.014 \\
160 & 1.35 & 0.000 & 1.000 & 0.000 & 0.007 & 0.004 \\
164 & 1.32 & 0.000 & 1.000 & 0.000 & 0.006 & 0.003 \\
320 & 0.68 & 0.000 & 1.000 & 0.000 & 0.002 & 0.001 \\
\hline
\end{tabular}

TABLE 4: Displacements ratios between bar MRF, shear wall models and TMD group systems.

\begin{tabular}{lcccccccccc}
\hline \multirow{2}{*}{ System } & \multicolumn{4}{c}{ One TMD } & \multicolumn{4}{c}{ Four TMD } \\
& 1 & 2 & 4 & 10 & 20 & 1 & 2 & 4 & 10 & 20 \\
\hline Bar MRF & 26 & 32 & 43 & 42 & 50 & 32 & 37 & 56 & 65 & 77 \\
\hline SW & 0.4 & 8 & 22 & 22 & 36 & 6 & 14 & 38 & 49 & 66 \\
\hline \multirow{3}{*}{ System } & \multicolumn{4}{c}{ Eight TMD } & & \multicolumn{5}{c}{ Sixteen TMD } \\
& 1 & 2 & 4 & 10 & 20 & 1 & 2 & 4 & 10 & 20 \\
\hline Bar MRF & 16 & 49 & 61 & 78 & 88 & 19 & 58 & 67 & 88 & 92 \\
\hline SW & 9 & 30 & 44 & 67 & 82 & 11 & 43 & 51 & 67 & 74 \\
\hline
\end{tabular}

and confirmed the merit of the MTMD in seismic applications. In terms of installation the merit of the MTMD with respect to a single TMD is that the MTMD consists of distributed dampers with small mass and generally does not require any devoted space to install them [11].

The proposed arrangement of TMD through the model is four systems to study the optimum design of TMD. The comparison will be done for a bare model MFR and a core shear wall model and one TMD $(1,2,4,10,20$ TMDs distributed on the elevation of the building as shown in Figure 4), 4 TMDs distributed on floor plan $(4 \times 1,4 \times 2$, $4 \times 4,4 \times 10,4 \times 20$ in inner core of the model), 8 TMDs distributed on floor plan $(8 \times 1,8 \times 2,8 \times 4,8 \times 10$, and $8 \times$ 20 in inner core of the model), and 16 TMDs distributed on floor plan $(16 \times 1,16 \times 2,16 \times 4,16 \times 10$, and $16 \times 20$ in inner core of the model number TMDs are equal to number of columns of model), as shown in Figures 5(a) and 5(b) in the distribution of TMDs devices on the horizontal plan and through the elevation of the model.

Table 3 illustrates values of the optimum parameters (spring stiffness $k_{d}$, damping coefficient of damper $c_{d}$, and relative damping $\zeta_{\mathrm{opt}}$ ) of several numbers of TMDs. For single TMD used in the model the numbers are 1, 2, 5, 10, and 20 distributed on each floor level. For 4 TMDs disabused on plan of model ( 4 in each floor), group of TMDs contains 4 TMDs which are $4 \times 1=4,4 \times 2=8,4 \times 5=20,4 \times 10=$ 40 , and $4 \times 20=80$. For 16 TMDs groups disabused on plan of model ( 16 in each floor for each column), group of TMDs contains 16 TMDs which are $16 \times 1=16,16 \times 2=32,16 \times$ $5=80,16 \times 10=160$, and $16 \times 20=320$.

\section{Results and Discussion}

Figure 6 shows the results of displacements of each floor under seismic load using several arrangements of TMDs. For all systems the ratios between displacements of model without and with shear wall are nearly 2 from the 3rd to 30th floors and 1.1 from 33rd to 60th floors. The highest performance of the arrangement group in reducing displacements of floors appear in $16 \times 20$ TMDs then $16 \times$ $10,8 \times 20,16 \times 7,8 \times 10,4 \times 20,16 \times 5,16 \times 4,4 \times 10,8 \times$ $4,16 \times 2,4 \times 5,20,8 \times 2,4,10,4 \times 2,2,4 \times 1,1,16 \times 1$, $8 \times 1$ TMDs. Table 4 summarized the results of displacements ratio between bar frame, SW model, and TMD groups.

Figure 7 shows the results of column shear forces in each floor under seismic load using several arrangements of TMDs. Figure 7(a) shows shear force for columns (1), and the ratio between base shear force of model without and with shear wall is nearly 2.4. Figure 7 (b) shows shear force for columns (2), and shear wall models reduce base shear of column (2) by nearly 2.64 times. Figure 7(c) shows shear force for columns (3), and shear wall model reduces base shear of column (3) by nearly 1.85 times. Figure 7(d) shows shear force for columns (4), and shear wall model reduces base shear of column (4) by nearly 1.53 times. Table 5 summarized the results of shear force of columns 1, 2, 3, and 4 ratios between bar frame, SW model, and TMD groups.

The performance of TMDs group arrangements in reducing shear force for column (1) is in the sequence 


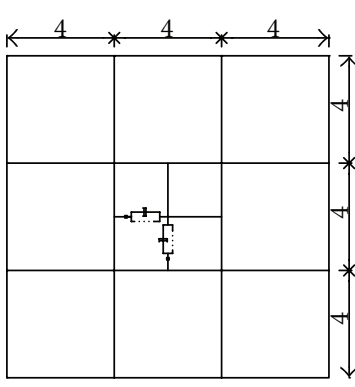

(i) One TMD

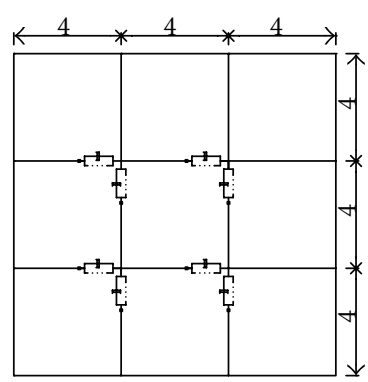

(ii) 4 TMDs group

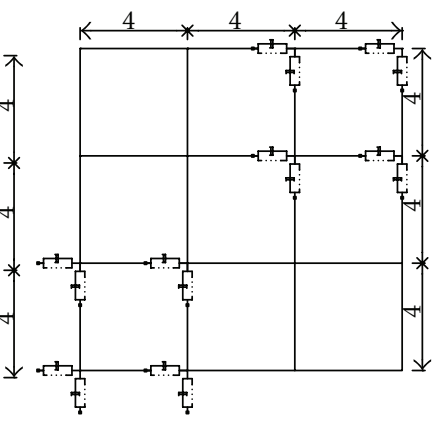

(iii) 8 TMDs group

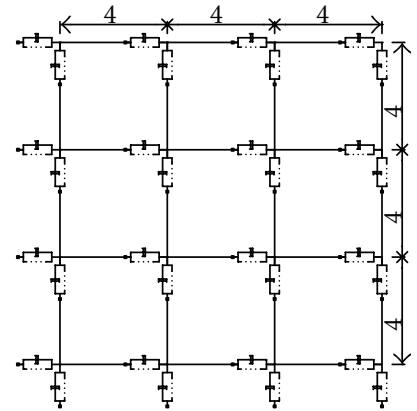

(iv) 16 TMDs group

(a) Horizontal arrangement of TMDs on floor plain

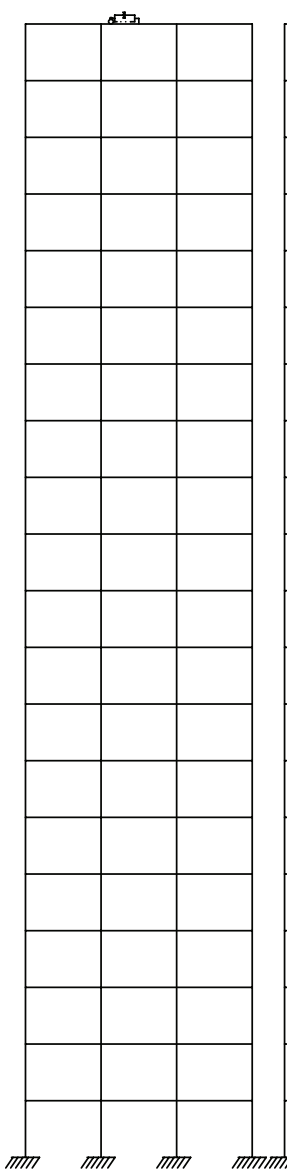

(i) One TMD

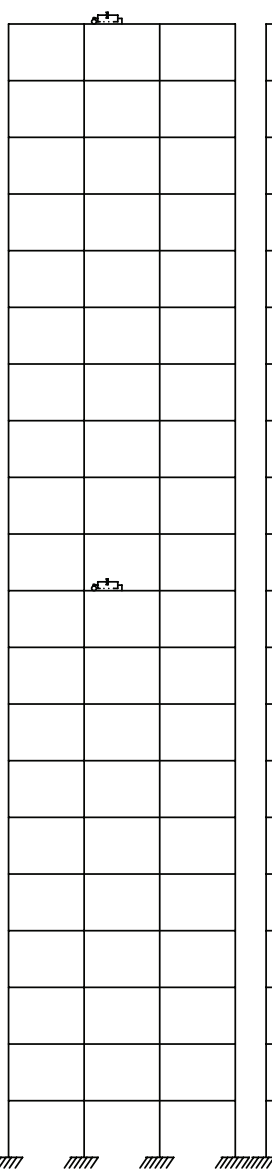

(ii) 2 TMDs

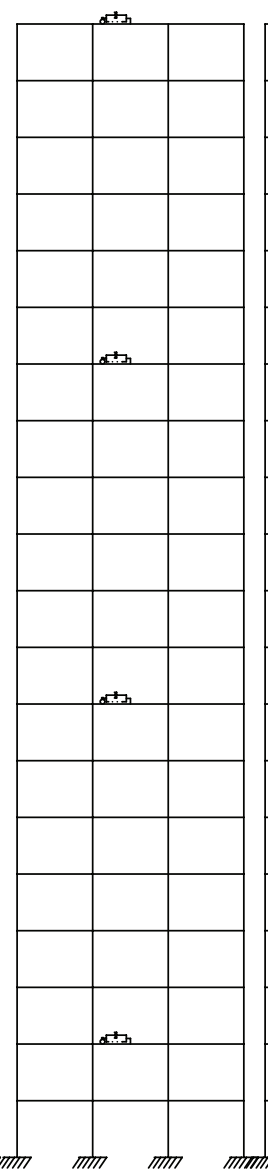

(iii) 4 TMDs

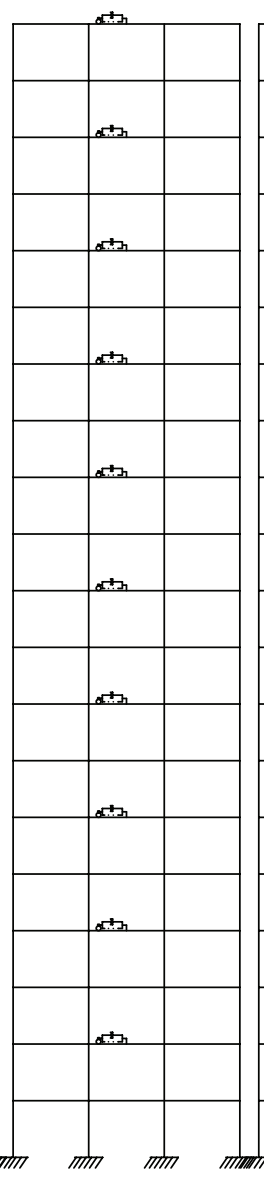

(iv) 10 TMDs

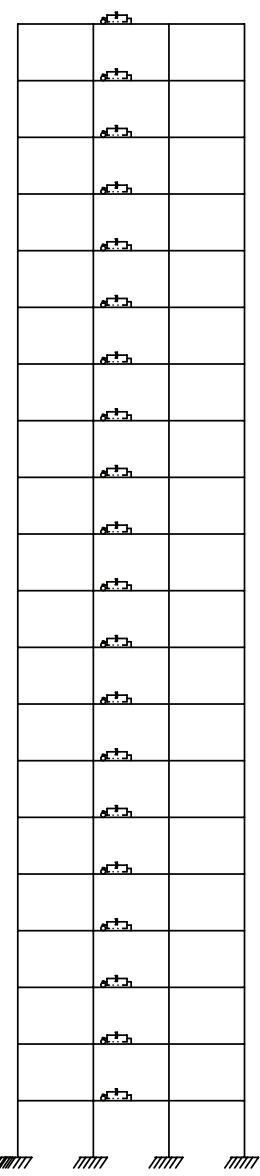

(v) 20 TMDs

(b) Vertical arrangement of TMDs on model elevation

$20 \times 16,10 \times 16,20 \times 8,20 \times 4,10 \times 8,5 \times 16,10 \times 4$, $4 \times 8,4 \times 5,20,10,4,2,4,2 \times 16,2 \times 8,2,1 \times 4,1,1 \times 8$, and $1 \times 16$. The performance of TMDs group arrangements in reducing shear force for column (2) is in the sequence $20 \times$ $16,20 \times 4,10 \times 16,20 \times 8,10 \times 8,10 \times 4,5 \times 16,20,4 \times 5$, $4 \times 8,4 \times 16,104,2 \times 4,2 \times 8,2,2 \times 16,1 \times 4,1,1 \times 8$, and $1 \times 16$. The performance of TMDs group arrangements in reducing shear force for column (3) is in the sequence 20 $\times 16,20 \times 8,10 \times 16,20 \times 4,7 \times 16,10 \times 8,5 \times 16,10 \times 4$,
$20,4 \times 16,4 \times 8,4 \times 5,4,10,2 \times 4,2 \times 16,2 \times 8,2,1$ $\times 4,1,1 \times 8$, and $1 \times 16$. The performance of TMDs group arrangements in reducing shear force for column (4) is in the sequence $20 \times 16,20 \times 4,20 \times 8,10 \times 16,10 \times 8,5 \times 16,10$ $\times 4,20,4 \times 5,4 \times 16,4 \times 8,10,4,2 \times 4,2 \times 8,2 \times 16,2,1$ $\times 4,1,1 \times 8$, and $1 \times 16$.

Arrangements of TMDs in floor plan (especially ones attached to columns) reduce the displacement in very effectiveness the distribution of TMDs with columns places 

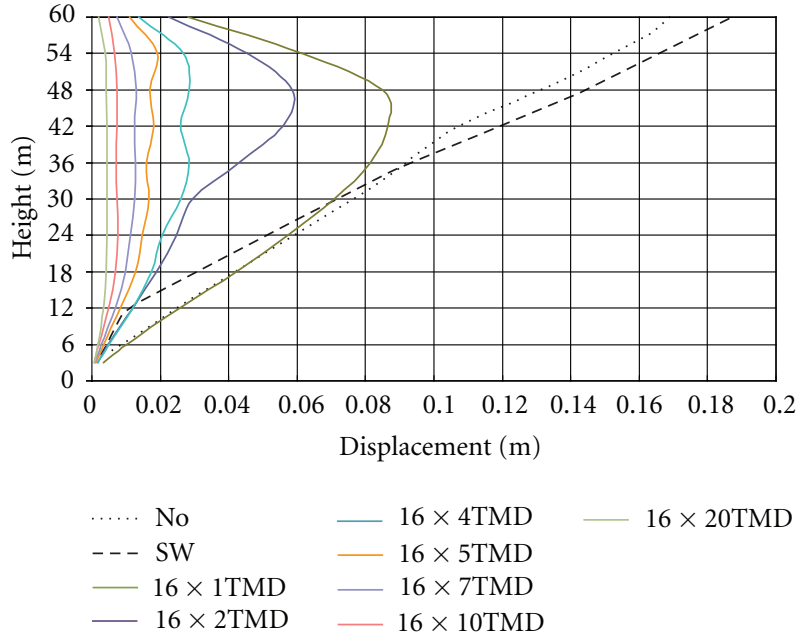

(i) Sixteen group TMD
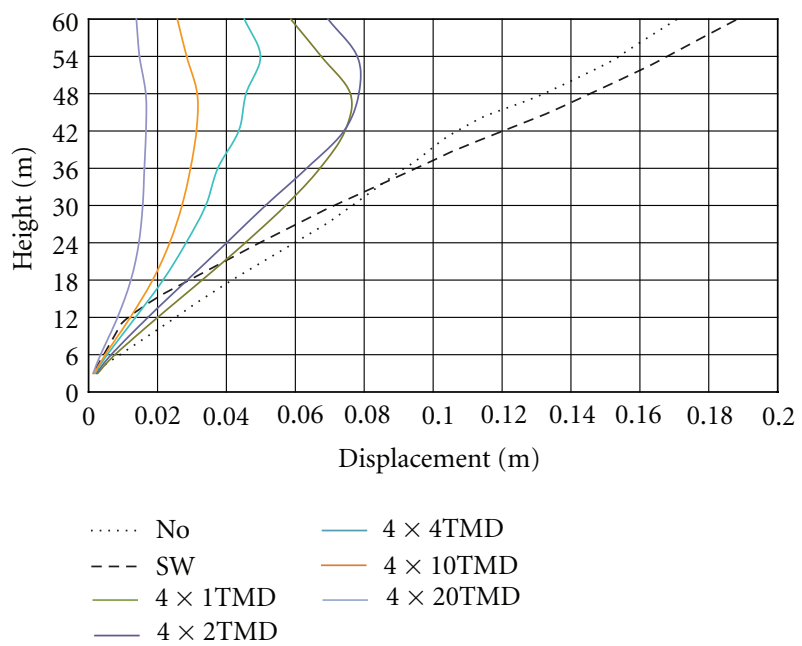

(iii) Four group TMD

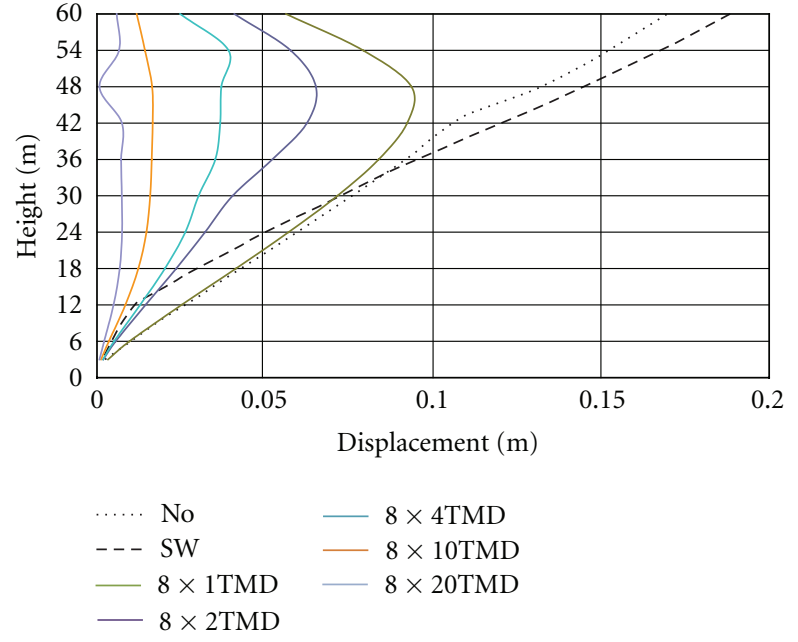

(ii) Eight group TMD

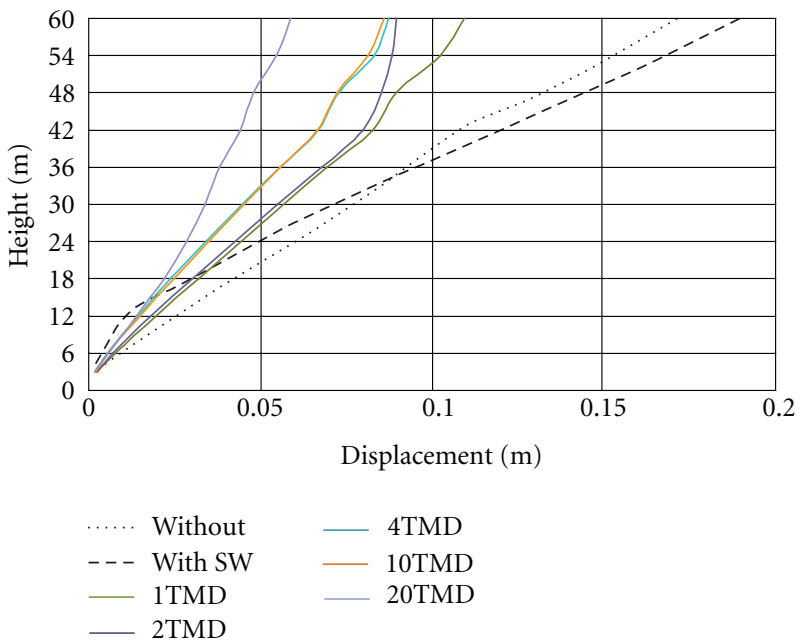

(iv) One TMD

FIGURE 6: Comparison of displacements of the model under seismic load with different arrangements of TMDs.

distribute the vibration forces on each TMD to reduce these effects and reduce. the shear force on each column. Lateral effect of seismic vibration distributed on vertical elements of the building (i.e., Columns) with a ratio of inertia of each element (equal inertia in this case) so, the attachment of TMDs devices on each column of the model or some numbers of the columns will affect considerably on reduction vibration of the model so that, the values of total displacements and shear forces in columns each floor.

Figure 8 illustrates the displacements versus base shear force of the models using different arrangements of TMDs groups. From the figures, using single TMD in the model creates a disturbance shape of the relation between displacements and base shear forces, using single TMD distributed through the elevation of the model creates a more undisturbance relation between displacements and base shear forces, using one group of TMDs (4, 8, 16 TMDs) in the top model will reduce the disturbance of the relation between top displacements and base shear forces, and using group of TMDs distributed on floor plan of the model through the elevation of the model shows nearly a linear relation between the displacements of top model and the base shear forces. The above discussion shows that the group of TMDs distributed on the floor plan of the model reduces the vibration of the model and the system is more effective especially for those distributed in floor plan and through the elevation of the model.

Figure 9 shows the frequency of the top point of the free and under various cases of using shear wall, single TMD, model and group of TMDs models. The frequency in both cases of free and shear wall models is nearly equals $(4 \mathrm{~Hz})$ and the acceleration is also nearly equal $\left(11.8 \mathrm{~m} / \mathrm{s}^{2}\right)$ but the values of frequency in models used TMDs especially a group of TMDs is reduced by nearly 2.5 times and the acceleration by nearly 4 times. The frequency when using a group of TMDs in the model is show a wide board frequency for the model. 


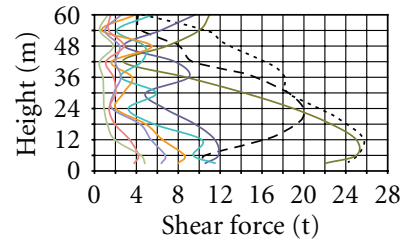

(i) Sixteen group TMD

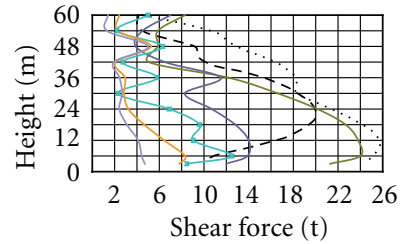

(ii) Eight group TMD

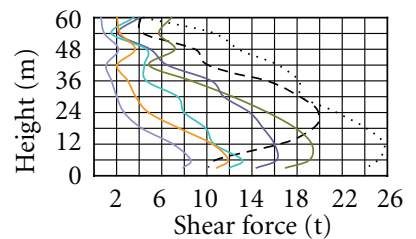

(iii) Four group TMD

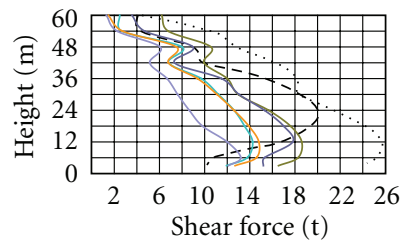

(iv) One TMD

(a) Shear force column (1)

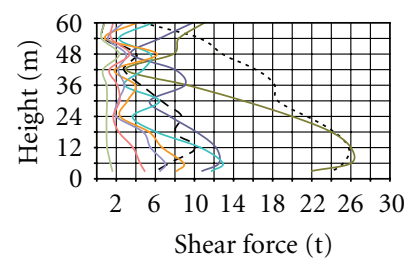

(i) Q (2) group $16 \mathrm{TMD}$

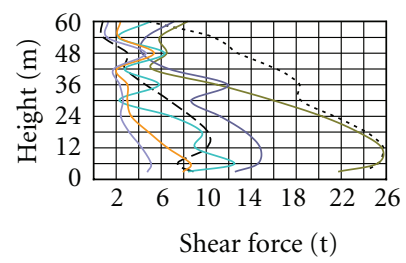

(ii) Q (2) group $8 \mathrm{TMD}$

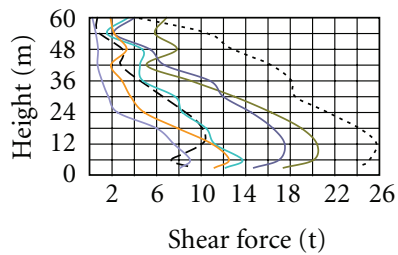

(iii) Q (2) group 4 TMD

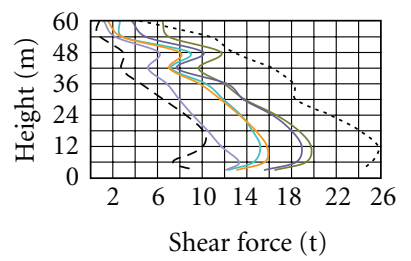

(iv) Q (2) one TMD

(b) Shear force column (2)

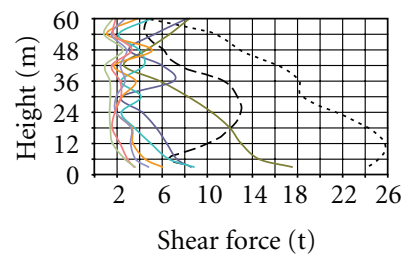

(i) Sixteen group TMD

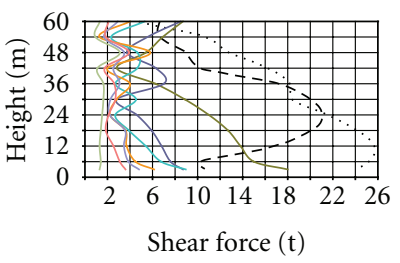

(i) Sixteen group TMD

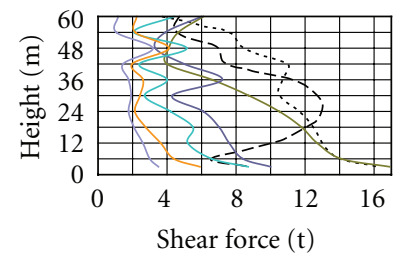

(ii) Eight group TMD

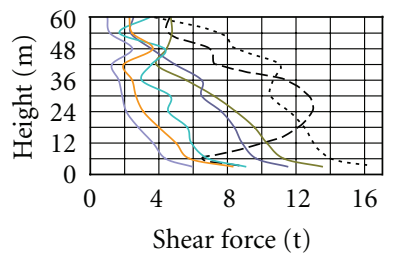

(iii) Four group TMD

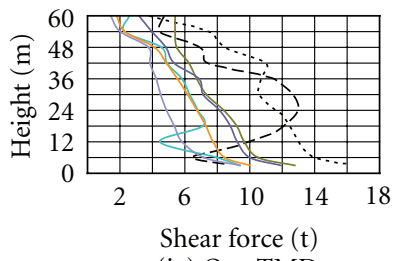

(iv) One TMD

(c) Shear force column (3)

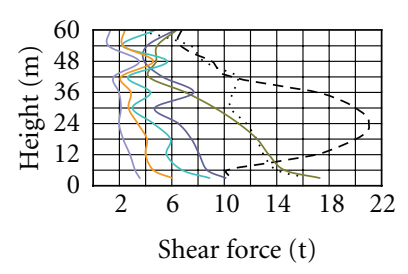

(ii) Eight group TMD

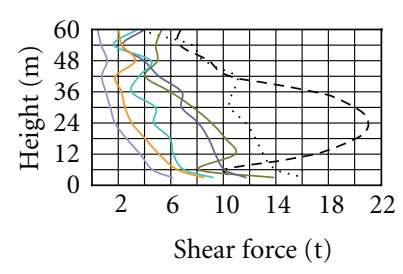

(iii) Four group TMD

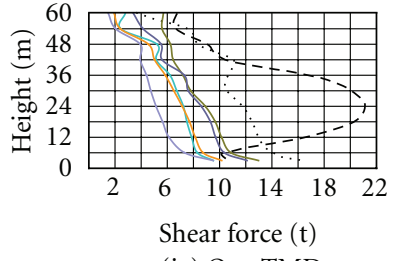

(iv) One TMD

(d) Shear force of column (4)

$$
\begin{aligned}
& -- \text { SW }-16 \times 5 \mathrm{TMD} \quad--\mathrm{SW} \quad 8 \times 4 \mathrm{TMD} \\
& -16 \times 1 \mathrm{TMD}-16 \times 7 \mathrm{TMD}-8 \times 1 \mathrm{TMD}-8 \times 10 \mathrm{TMD} \\
& -16 \times 2 \mathrm{TMD}-16 \times 10 \mathrm{TMD} \\
& -8 \times 2 \mathrm{TMD}-8 \times 20 \mathrm{TMD}
\end{aligned}
$$

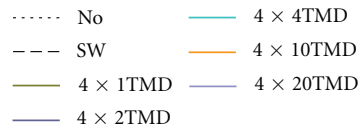

$$
\begin{aligned}
& \begin{array}{ll}
-\ldots . \text { No } & \text { No } \\
--- & \text { SW } \\
- \text { 1TMD } \\
- \text { 1TMD } & \text { 10TMD } \\
- \text { 20TMD } \\
\hline \text { 2TMD }
\end{array}
\end{aligned}
$$

FIGURE 7: Comparison of shear forces of the model under seismic load with different arrangements of TMDs.

Figure 10 illustrates the comparison of vibration of displacements and shear force of the models with and without using TMDs. The vibration of the top displacements and base shear of the model use TMD shown in the figures in light colors. Figure 10(a) (left) shows the effect of using 4 single TMDs in the model on reduction of the displacements of shear wall (SW) model and Figure 10(a) (right) shows the effect of use 4 single TMDs in the model on base shear with respect to SW model; the effect on base shear shows nearly that both vibrations are equal. Figure 10(b) (right) shows the effect of using group 4 TMDs (distributed on floor plan) in the model on reduction of the displacements of free model and Figure 10(b) (left) shows the effect of using group 4 TMDs in the model on base shear with respect to free model; the effect on base shear shows nearly that both vibrations are equal. Figure 10(c) (left) shows the effect of using group $4 \times 20$ TMDs (distributed on floor plan through the model) in the model on reduction of the displacements of SW model and Figure 10(c) (right) shows the effect of using group $4 \times 20$ TMDs in the model on base shear 
TABLE 5: Shear forces ratios between bar MRF, shear wall models and TMD group systems.

(a) Column (1)

\begin{tabular}{lcccccccccc}
\hline \multirow{2}{*}{ System } & \multicolumn{4}{c}{ One TMD/floor } & \multicolumn{4}{c}{ Four TMD/floor } \\
& 1 & 2 & 4 & 10 & 20 & 1 & 2 & 4 & 10 & 20 \\
\hline Bar MRF & 23 & 35 & 47 & 49 & 60 & 29 & 43 & 59 & 69 & 82 \\
\hline SW & -6 & 2 & 21 & 33 & 36 & -2 & 15 & 37 & 50 & 70 \\
\hline \multirow{3}{*}{ System } & \multicolumn{4}{c}{ Eight TMD/floor } & \multicolumn{5}{c}{ Sixteen TMD/floor } \\
& 1 & 2 & 4 & 10 & 20 & 1 & 2 & 4 & 10 & 20 \\
\hline Bar MRF & 23 & 46 & 64 & 75 & 83 & 8 & 43 & 72 & 85 & 89 \\
\hline SW & -5 & 19 & 44 & 61 & 74 & 5 & 14 & 58 & 77 & 82 \\
\hline
\end{tabular}

Positive singes indicate reduction; negative singes indicate increase.

(b) Column (2)

\begin{tabular}{|c|c|c|c|c|c|c|c|c|c|c|}
\hline \multirow{2}{*}{ System } & \multicolumn{5}{|c|}{ One TMD/floor } & \multicolumn{5}{|c|}{ Four TMD/floor } \\
\hline & 1 & 2 & 4 & 10 & 20 & 1 & 2 & 4 & 10 & 20 \\
\hline Bar MRF & 20 & 31 & 44 & 47 & 60 & 26 & 40 & 58 & 70 & 84 \\
\hline SW & -182 & -171 & -136 & -144 & -133 & -191 & -162 & -134 & -123 & 11 \\
\hline \multirow{2}{*}{ System } & \multicolumn{5}{|c|}{ Eight TMD/floor } & \multicolumn{5}{|c|}{ Sixteen TMD/floor } \\
\hline & 1 & 2 & 4 & 10 & 20 & 1 & 2 & 4 & 10 & 20 \\
\hline Bar MRF & 22 & 44 & 64 & 75 & 83 & 7 & 40 & 70 & 83 & 92 \\
\hline SW & -240 & -139 & 7 & 12 & 47 & -242 & -119 & 10 & 29 & 46 \\
\hline
\end{tabular}

Positive singes indicate reduction; negative singes indicate increase.

(c) Column (3)

\begin{tabular}{lccccccccccc}
\hline \multirow{2}{*}{ System } & \multicolumn{3}{c}{ One TMD/floor } & \multicolumn{4}{c}{ Four TMD/floor } \\
& 1 & 2 & 4 & 10 & 20 & 1 & 2 & 4 & 10 & 20 \\
\hline Bar MRF & 23 & 33 & 47 & 47 & 58 & 27 & 40 & 54 & 64 & 77 \\
\hline SW & 4 & 15 & 34 & 32 & 44 & 9 & 24 & 42 & 53 & 69 \\
\hline \multirow{3}{*}{ System } & \multicolumn{4}{c}{ Eight TMD/floor } & \multicolumn{5}{c}{ Sixteen TMD/floor } \\
& 1 & 2 & 4 & 10 & 20 & 1 & 2 & 4 & 10 & 20 \\
\hline Bar MRF & 22 & 41 & 57 & 71 & 80 & 6 & 35 & 64 & 76 & 82 \\
\hline SW & 1 & 28 & 46 & 62 & 75 & 1 & 22 & 57 & 71 & 77 \\
\hline
\end{tabular}

Positive singes indicate reduction; negative singes indicate increase.

(d) Column (4)

\begin{tabular}{lcccccccccc}
\hline \multirow{2}{*}{ System } & \multicolumn{4}{c}{ One TMD/floor } & \multicolumn{4}{c}{ Four TMD/floor } \\
& 1 & 2 & 4 & 10 & 20 & 1 & 2 & 4 & 10 & 20 \\
\hline Bar MRF & 18 & 29 & 41 & 44 & 56 & 25 & 35 & 53 & 65 & 82 \\
\hline SW & 30 & 39 & 50 & 51 & 60 & 37 & 45 & 59 & 67 & 82 \\
\hline \multirow{3}{*}{ System } & \multicolumn{4}{c}{ Eight TMD/floor } & \multicolumn{5}{c}{ Sixteen TMD/floor } \\
& 1 & 2 & 4 & 10 & 20 & 1 & 2 & 4 & 10 & 20 \\
\hline Bar MRF & 18 & 38 & 54 & 67 & 79 & 1 & 31 & 61 & 73 & 83 \\
\hline SW & 28 & 47 & 60 & 71 & 81 & 16 & 44 & 68 & 77 & 87 \\
\hline PW
\end{tabular}

Positive singes indicate reduction; negative singes indicate increase.

with respect to SW model; the effect on base shear show that vibration of TMDs group reduced by nearly 2.5 times than SW model. Figure 10(d) (left) shows the effect of using group $8 \times 20$ TMDs (distributed on floor plan through the model) in the model on reduction of the displacements of SW model.

\section{Conclusion}

The present paper studies the seismic behavior on tall buildings structure through using the TMD system. The purpose of the study is to investigate TMDs device that not only provides adequate energy dissipation by different 


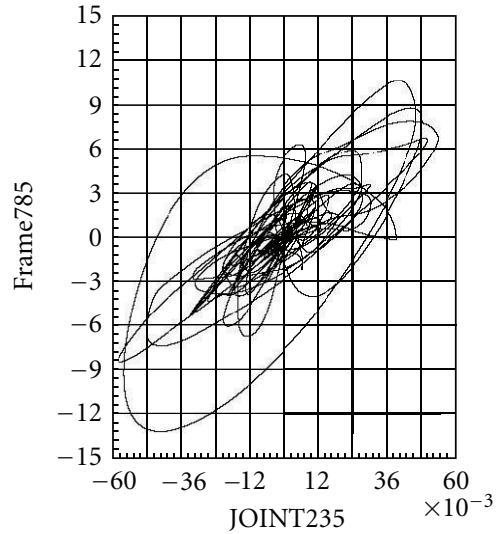

(i) $1 \times 4 \mathrm{TMD}$

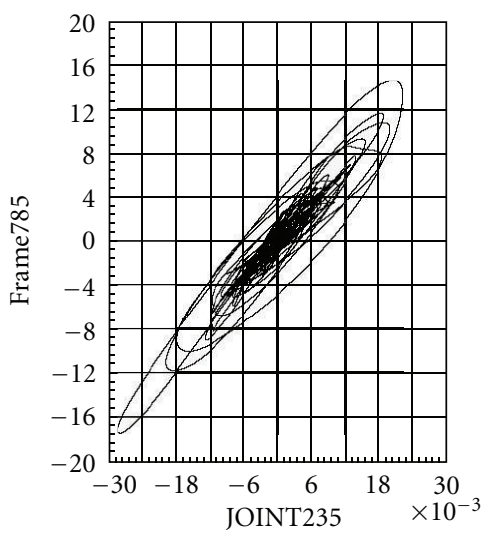

(vi) $16 \times 1 \mathrm{TMD}$

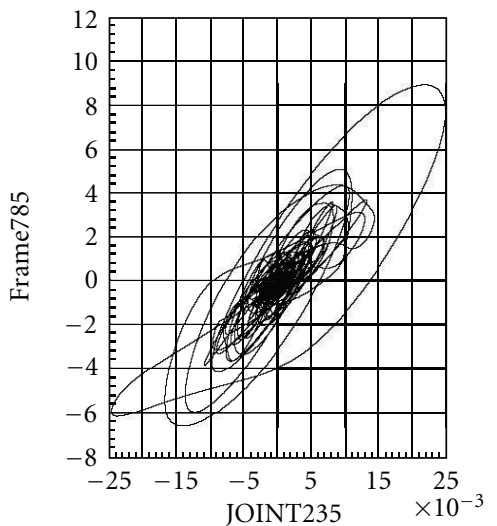

(vii) $8 \times 1 \mathrm{TMD}$

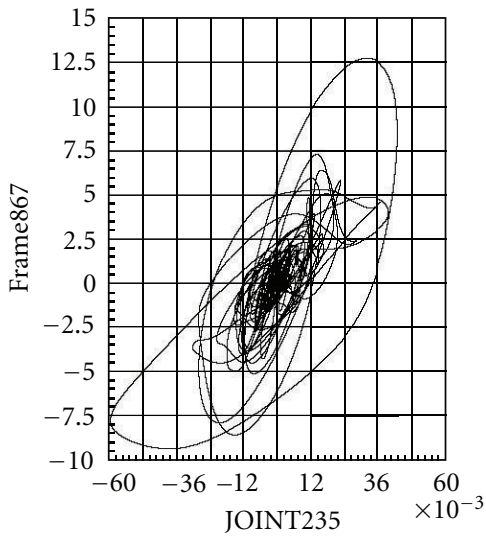

(ii) $1 \times 20 \mathrm{TMD}$

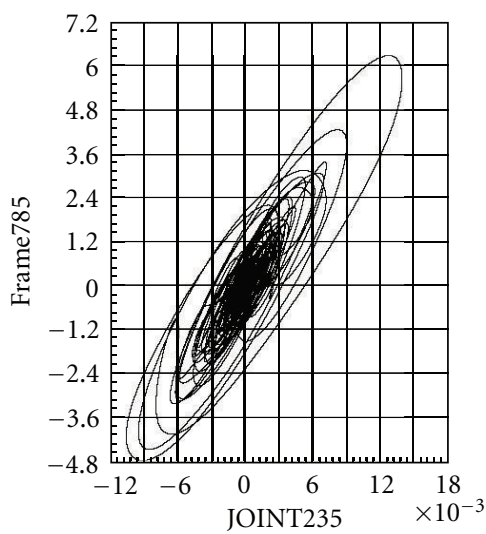

(v) $8 \times 20 \mathrm{TMD}$

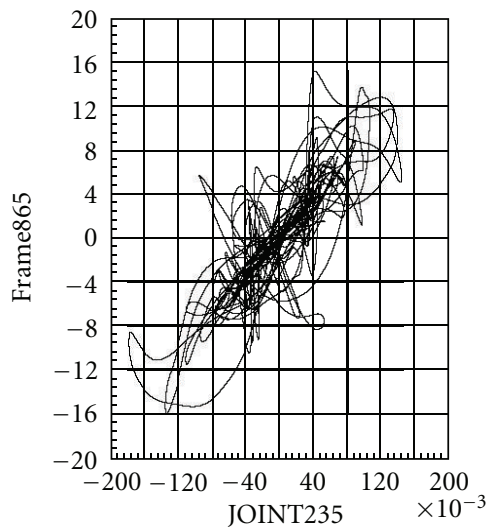

(viii) No TMD and SW

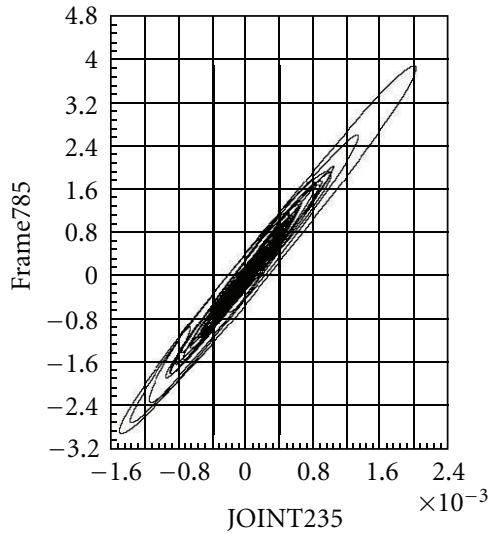

(iii) $16 \times 20 \mathrm{TMD}$

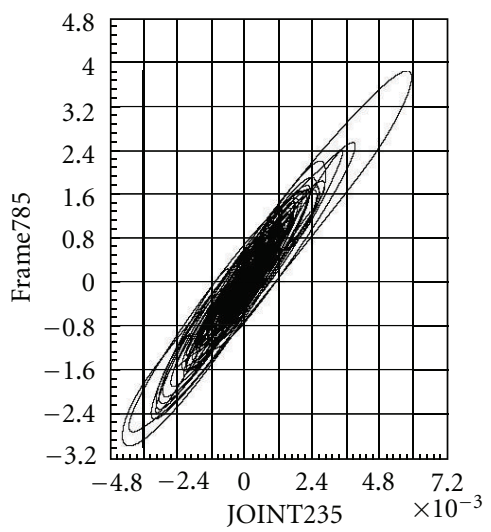

(vi) $4 \times 20 \mathrm{TMD}$

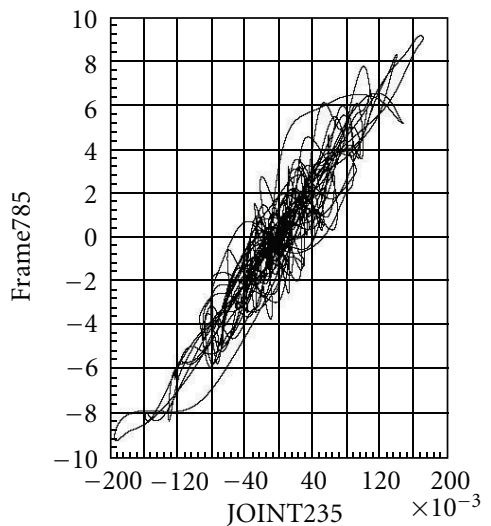

(ix) SW only

FIGURE 8: Trajectories of base shear and displacements with and without use TMDs.

models, but also is easy to install and tested. In addition, these are not like cross-bracings which may be undesirable in the field of aesthetically and architecturally.

The following conclusions can be drawn from the present study.

(1) The results show that, generally, the response of structure can be dramatically reduced by using TMDs. But it should be mentioned that, although this study produced results which corroborate the findings of a great deal of the previous work in this field, according to time history analysis (El Centro earthquake), the results of this study show significant decrease in shear forces.

(2) One of the most significant findings to emerge from this study is that, with increasing the amount of dynamic amplitude, the reduction percentage of response of structure due to applying TMDs has been raised too. In other words, it can be understood 


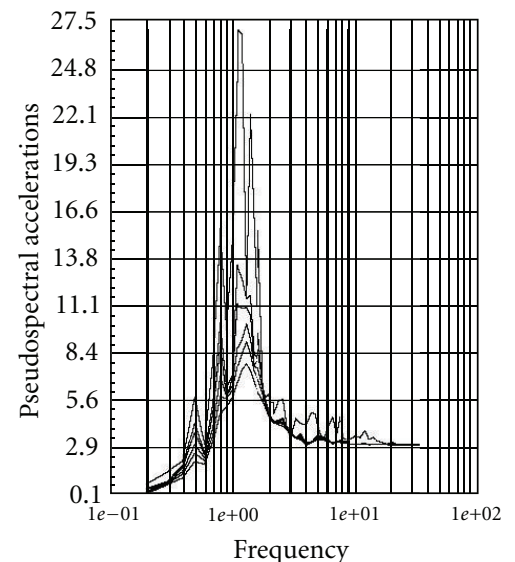

(i) $1 \times 20 \mathrm{TMD}$

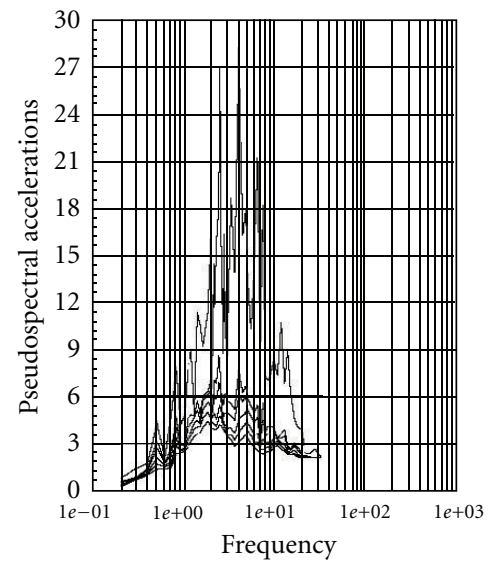

(iv) $16 \times 20 \mathrm{TMD}$

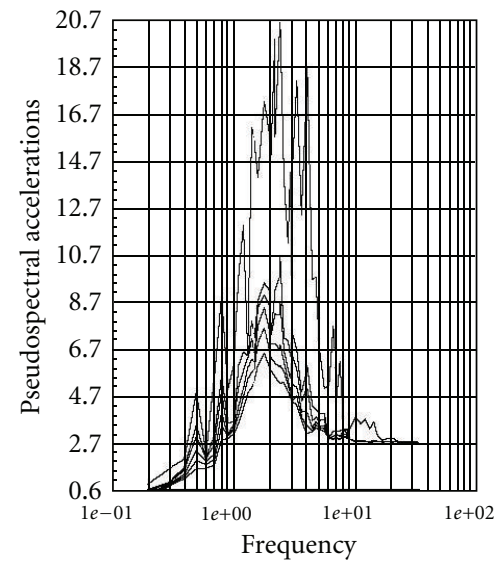

(ix) $4 \times 20 \mathrm{TMD}$

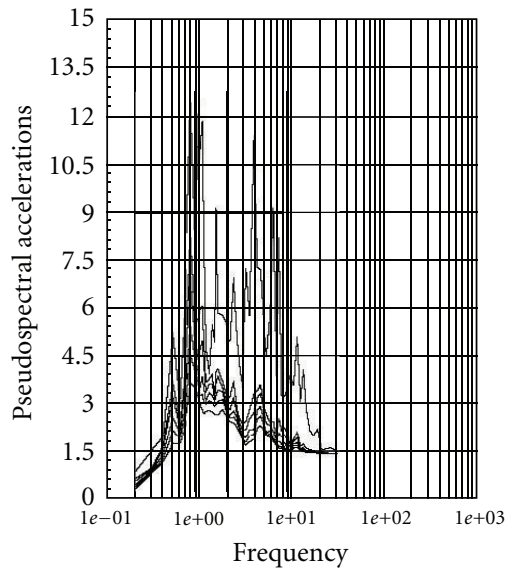

(ii) $1 \times 16 \mathrm{TMD}$

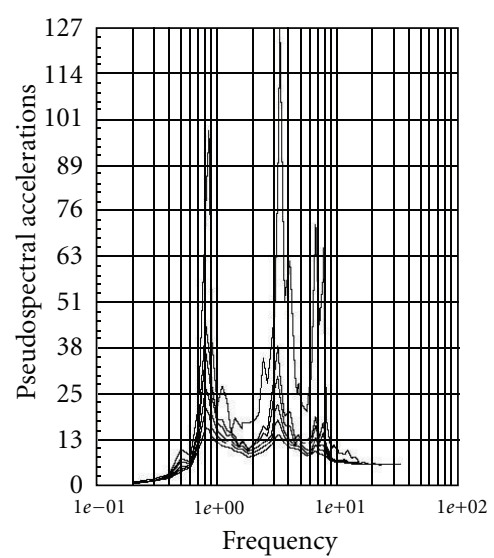

(vi) SW only

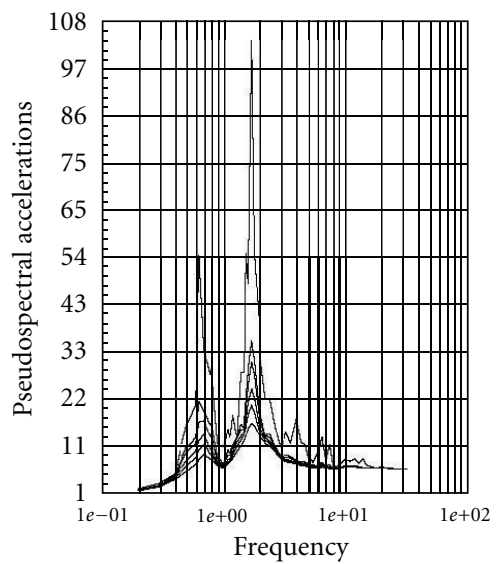

(x) No TMD and SW

FIGURE 9: Frequency versus pseudospectral acceleration.

that, whatever is the amount of dynamic amplitude increase, the performance of TMDs is much better.

(3) Single TMD is better used when distributed through the elevation of the model; this will reduce both overall displacements and base shear forces but also these models must use SW to control the lateral effect of the earthquake.
(4) Using group of TMDs distributed on the floor plan of the model will affect more the reduction of displacements and shear force especially those how distributed in the elevation of the model which will be the solution of resisting earthquake completely for both undesirable effects of it (large displacements and shear force in columns). 

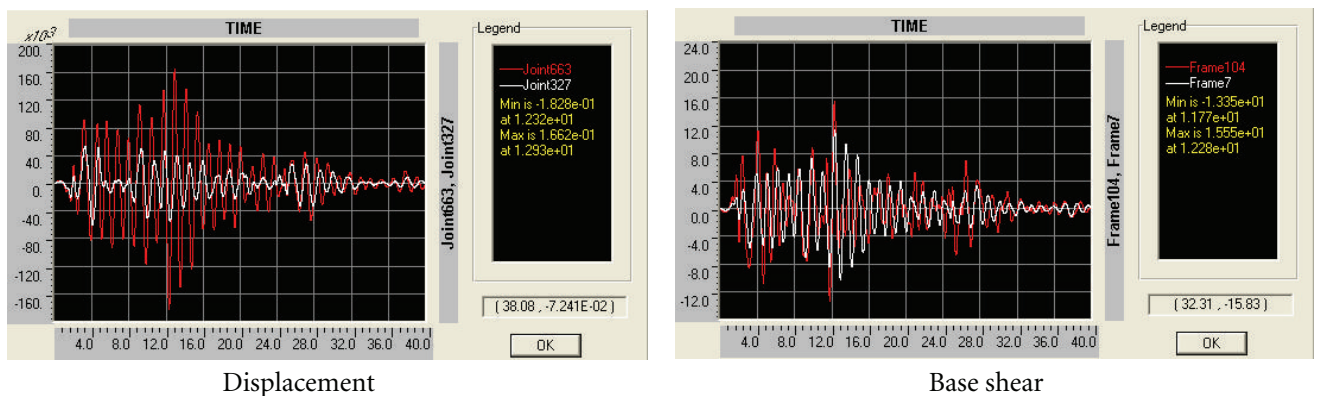

(a) Comparison of 4 TMDs on floor plan and SW model
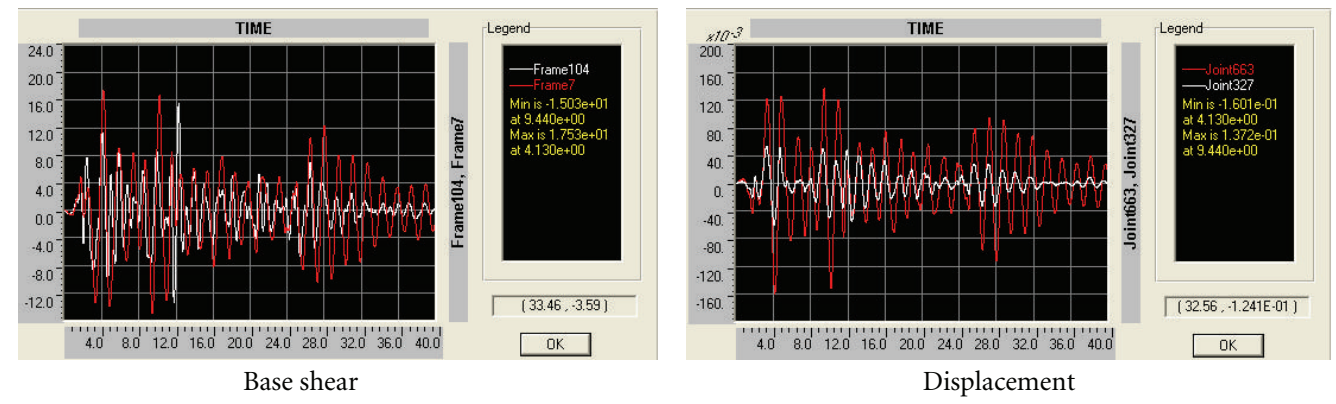

(b) Comparison between $4 \times 1$ TMDs on elevation and free model
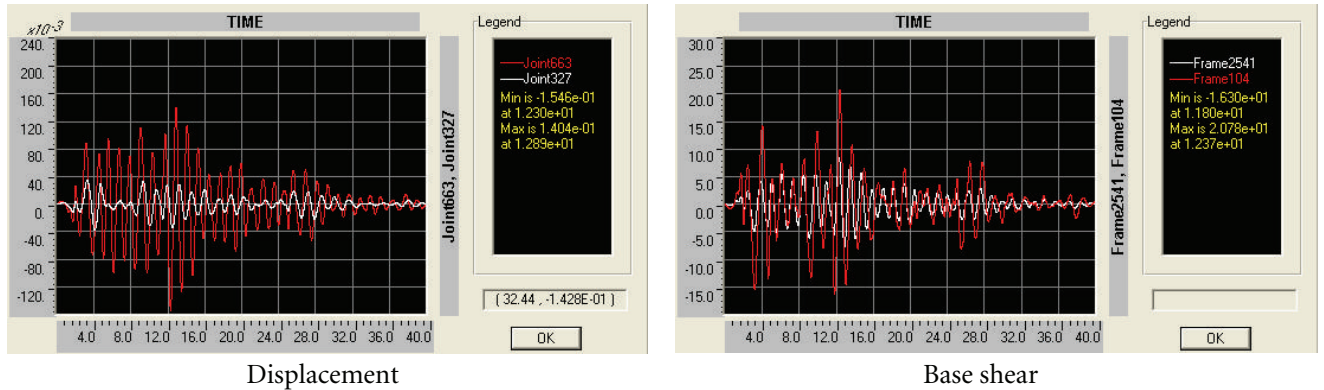

(c) Comparison between $4 \times 20$ TMDs distributed on floor plan and elevation and SW model
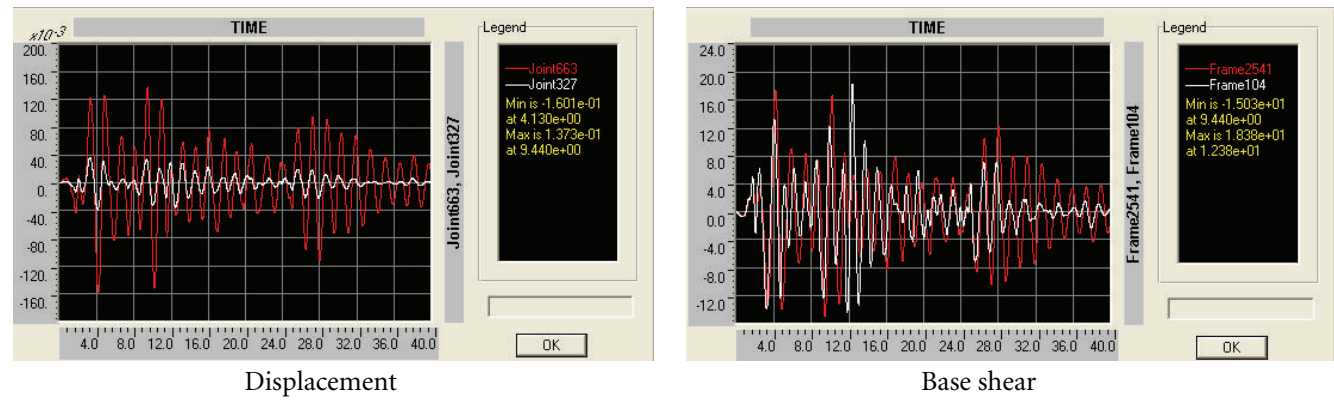

(d) Comparison between $4 \times 20$ TMDs distributed on floor plan and elevation and free model

FIGURE 10: Comparison between the vibrations of top point displacement and base shear force in model with and without TMDs.

(5) Group $16 \mathrm{TMDs}$ are very effective for reducing both displacements and shear force than any lateral resistance method but it is uneconomic; using group 4 TMDs distributed on floor plan staggered through the elevation of the model gives much better results than SW model and is more economic.
The best using of TMDs is distributing them on the floor plan of the buildings and through the elevation of them to control the vibration in each floor level effectively.

Finally, for the future researches, the practical application of using TMD group in reducing both displacements and shear forces in the high rise buildings are recommended by 
use a prototype of building on a shaking table to improve the results.

\section{References}

[1] J. P. Den Hartog, Mechanical Vibrations, McGraw-Hill, New York, NY, USA, 4th edition, 1956.

[2] A.C. Webster and R. Vaicaitis, "Application of tuned mass dampers to control vibrations of composite floor systems," Engineering Journal/American Institute of Steel Construction Third Quarter/1992, pp. 116-124, 1992.

[3] K. I. Al-Hulwah, Floor vibration control using three degree of freedom tuned massdampers, Ph.D. thesis, The School of Engineering, University of Dayton, 2005.

[4] J. W. Smith, Vibration of Structures Application in Civil Engineering Design, Chapman and Hall, 1988.

[5] A. P. Wang and Y. H. Lin, "Vibration control of a tall building subjected to earthquake excitation," Journal of Sound and Vibration, vol. 299, no. 4-5, pp. 757-773, 2007.

[6] S. S. Tezcan and O. Uluca, "Reduction of earthquake response of plane frame buildings by viscoelastic dampers," Engineering Structures, vol. 25, no. 14, pp. 1755-1761, 2003.

[7] K. Iwanami and K. Seto, "Optimum design method for the dual dynamic damper and its effectiveness," Proceedings of the Japan Society of Mechanical Engineering, vol. 50, no. 449, pp. 44-52, 1984 (Japanese).

[8] T. Igusa and $\mathrm{K} . \mathrm{Xu}$, "Vibration control using multiple tuned mass dampers," Journal of Sound and Vibration, vol. 175, no. 4, pp. 491-503, 1994.

[9] C. Li, "Optimum multiple tuned mass dampers for structures under the ground acceleration based on DDMF and ADMF," Earthquake Engineering and Structural Dynamics, vol. 31, no. 4, pp. 897-919, 2002.

[10] C. Li and Y. Liu, "Further characteristics for multiple tuned mass dampers," Journal of Structural Engineering, vol. 128, no. 10, pp. 1362-1365, 2002.

[11] C. Li and Y. Liu, "Optimum multiple tuned mass dampers for structures under the ground acceleration based on the uniform distribution of system parameters," Earthquake Engineering and Structural Dynamics, vol. 32, no. 5, pp. 671-690, 2003.

[12] F. Sadek, B. Mohraz, A. W. Taylor, and R. M. Chung, "A method of estimating the parameters of tuned mass dampers for seismic applications," Earthquake Engineering and Structural Dynamics, vol. 26, no. 6, pp. 617-635, 1997.

[13] R. Villaverde, "Reduction in seismic response with heavilydamped vibration absorbers," Earthquake Engineering \& Structural Dynamics, vol. 13, no. 1, pp. 33-42, 1985.

[14] S. M. Zahrai and A. Ghannadi-Asl, "Seismic performance of TMDs in improving the response of MRF buildings," Scientia Iranica, vol. 15, no. 1, pp. 21-33, 2008. 

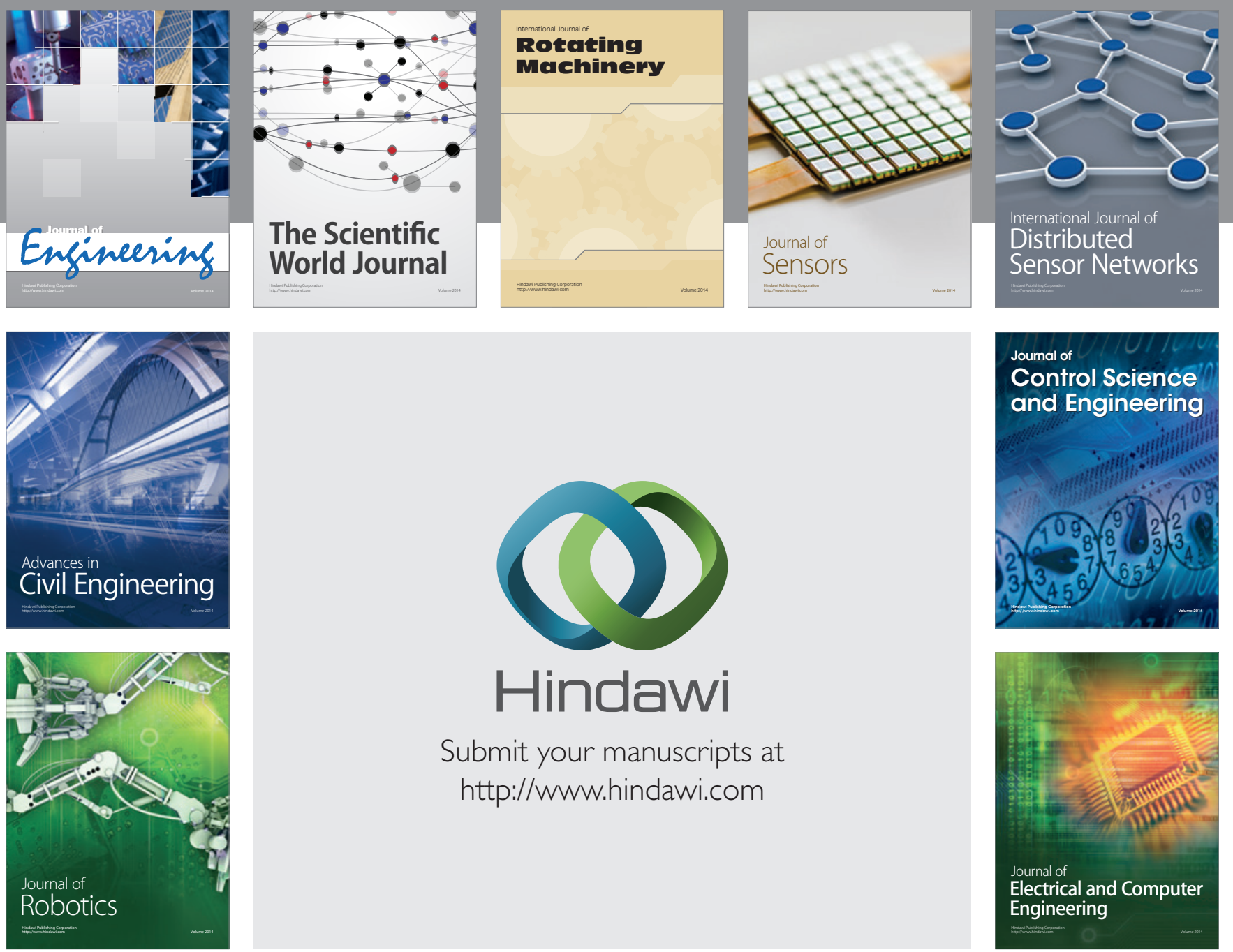

Submit your manuscripts at

http://www.hindawi.com
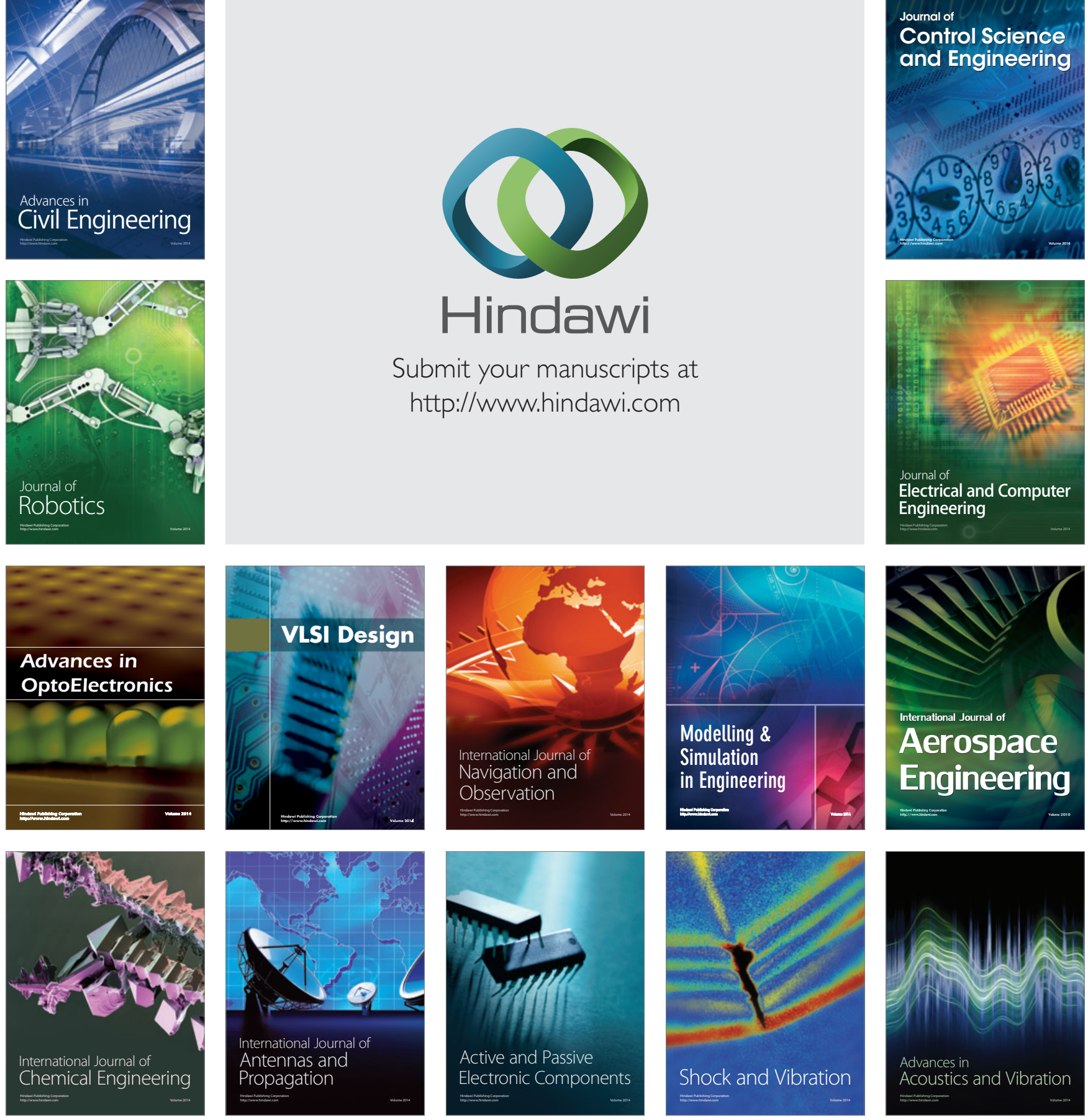